\title{
More Bang for Your Buck: How to Improve the Incentive Structure for Indigent Defense Counsel
}

\author{
Benjamin Schwall*
}

\begin{abstract}
The payment system and related incentive structure can have a major effect on an attorney's behavior, and this impact is somewhat predictable. Using data from the South Carolina Commission on Indigent Defense, we provide some evidence of how paying attorneys a flat fee can impact their behavior compared to paying them an hourly rate. Unsurprising, the effect is that attorneys put forth less effort when being paid a flat fee. It is important to recognize the trade-offs between controlling costs and providing effective representation that any payment system possesses. Using economic theory and a simple model, we discuss the various benefits and drawbacks of the different payment systems that are common for indigent defense attorneys. Finally, we discuss how the different payment systems can be improved to better align the attorney's interests with the State's interests.
\end{abstract}

\section{INTRODUCTION}

In the landmark case of Gideon v. Wainwright, ${ }^{1}$ the United States Supreme Court ruled that State governments are required to provide counsel for defendants in felony cases who are unable to afford it on their own. The Court later expanded this rule to any defendant who may face imprisonment in Argersinger v. Hamlin. ${ }^{2}$ The result has been that counties and States across the United States have combined to spend more than $\$ 5.3$ billion a year to represent more than four million indigent defendants. ${ }^{3}$ While the Gideon and Argersinger decisions made

* The author received his J.D. from Marquette University in 2011 and is currently a graduate student in the John E. Walker Department of Economics at Clemson University, hoping to finish his Ph.D. in May 2017. He can be reached via email at bschwal@ clemson.edu.

1 Gideon v. Wainwright, 372 U.S. 335 (1963).

2 Argersinger v. Hamlin, 407 U.S. 25 (1972).

3 Holly R. Stevens et al., State, County and Local Expenditures for Indigent DeFENSE SERVICES FisCAL YEAR 2008, at 7 (2010), http://www.americanbar.org/content/dam/aba/ administrative/legal_aid_indigent_defendants/ls_sclaid_def_expenditures_fy08.authcheckdam.pdf [https://perma.cc/DD9P-XLYL]. 
the provision of counsel mandatory for indigent defendants, they offered no guidance as to how the States should accomplish it. One thing is clear: each State must attempt to balance the trade-off between ensuring that the service provided to all defendants meets the requirement of effective counsel ${ }^{4}$ while operating with a budget constraint.

A key to addressing this trade-off - that is, how States can get the "best" representation for the money they spend-is understanding how different payment systems will affect an attorney's behavior for a particular case. Even if two systems pay the same total amount, the structure of the payment system can produce vastly different results by creating incentives for the attorney to take one action over another. If the State does not understand what actions its payment structure is incentivizing, there will be unintended consequences.

The goal of this paper is to use a simple economic model to explain the theoretical consequences of various indigent defense systems. The model will emphasize the fundamental economic principle that incentives matter and that people will respond in predictable ways to changes in incentives. Using the assumption that attorneys are utility-maximizing individuals, the model will show how different payment structures can affect attorney behavior. The model's primary result is to demonstrate how the different payment systems affect attorney hours spent on cases (both reported hours and hours actually worked). Economic theory also allows us to discuss the types of activities an attorney might perform under the different systems. Thus, this paper discusses the possible unintended consequences that each system is most likely to create based on the behavior that it incentivizes.

Additionally, we provide empirical evidence of how attorneys respond to different incentive structures. In 2012, South Carolina reformed its Indigent Defense System along several dimensions with respect to how attorneys from the private bar are compensated when they handle indigent defense cases. The main change shifted the payment system from an hourly rate to a flat fee per case. Data provided by the South Carolina Commission on Indigent Defense demonstrate how incentives can alter attorney behavior. ${ }^{5}$ The effect was dramatic, as the mean number of hours reported dropped by more than $50 \% .^{6}$ The rest of the paper proceeds as follows: Part II frames the discussion by explaining the basic principal-agent problem that must be considered in crafting incentive structures through indigent defense payment systems. Part III describes the economic model and the consequences that different incentive structures can produce. Part IV discusses the empirical evidence that supports the theoretical model. Part V discusses how the incentive structure can be improved. Part VI offers some concluding remarks.

\footnotetext{
4 See Strickland v. Washington, 466 U.S. 668 (1984).

5 See infra Part IV.

$6 \quad$ Id.
} 


\section{THE PRINCIPAL-AGENT PROBLEM}

A fundamental problem in economics is the principal-agent problem. The principal-agent problem arises when one party, the principal, hires another party, the agent, to act on his behalf. The issue is that the agent may have interests that do not align with the principal's interest. ${ }^{7}$ Thus, the agent might take actions that the principal would not approve. ${ }^{8}$ The general problem is compounded by the fact that the principal cannot perfectly observe either the agent's effort or output. In a world of perfect information, the principal would be able to use any incentive scheme to produce the optimum output. The only way the principal can prevent this is to perfectly observe the agent's effort and output. ${ }^{9}$ Since this is not feasible, the principal is left trying to design an incentive scheme that produces the "secondbest" solution. ${ }^{10}$

The basic idea of the second-best solution is that the principal should incentivize the agent to take actions that achieve production closest to the optimal ${ }^{11}$ outcome. In other words, the principal can influence, or constrain, the agent's action by choosing to compensate the agent either for inputs (such as time, effort, or resources invested) or outputs (such as work product or goals accomplished). ${ }^{12}$ In some situations, the idea of second-best instructs the principal to pay based on the agent's inputs, but, in other situations it will be better to pay based on the output. There is vast theoretical literature that predicts when one incentive structure is better than another. ${ }^{13}$ The general consensus is that the principal should compensate the agent for actions that are observable. ${ }^{14}$ To illustrate the principal-agent problem, let us consider the example of a couple who hires a real estate agent to sell their house. We will assume that the couple would like the real estate agent to get the highest sales price possible and would be willing to wait to

7 See Kathleen M. Eisenhardt, Agency Theory: An Assessment and Review, 14 ACAD. MGMT. REV. 57, 58 (1989).

$8 \quad$ Id.

9 See Kenneth J. Arrow, Inst. For Mathematical Stud. in the Soc. Sci, The Economics OF AGENCY 1-2 (1984).

10 Sanford J. Grossman \& Oliver D. Hart, An Analysis of the Principal-Agent Problem, 51 ECONOMETRICA 7, 14-15 (1983).

11 Optimal means that the maximum payoff for each party is realized.

12 See R.G. Lipsey \& Kelvin Lancaster, The General Theory of Second Best, 24 REV. ECON. STUD. 11 (1956-1957).

13 See, e.g., Grossman \& Hart, supra note 10; Armen A. Alchian \& Harold Demsetz, Production, Information Costs, and Economic Organization, 62 AM. ECON. ReV. 777 (1972); Bengt Holmstrom \& Paul Milgrom, Multitask Principal-Agent Analyses: Incentive Contracts, Asset Ownership, and Job Design, 7 J. L. ECON. \& ORG. 24 (1991).

14 See Holmstrom \& Milgrom, supra note 13. 
get it. ${ }^{15}$ We will assume that the agent is a profit-maximizing individual and wants to maximize the difference between her pay and any opportunity costs. By opportunity cost, we mean both any real costs that the agent must pay out and also the value of her next best alternative. This would include any compensation or other benefit that she might be foregoing from trying to sell another house. For example, by trying to sell another house she might make more money, or make the same amount of money but do so with a lower investment of time, effort, and resources.

The principal-agent problem arises in this context because the couple does not know the best price for their house, since the market determines the price at the time that the seller is attempting to sell the house, nor are they able to observe the effort of the agent. Let us consider two possible payment structures: paying the agent strictly for effort (the input) or paying the agent strictly for successfully selling the house (the output). First, we will consider the situation where the couple compensates the agent for her inputs by either paying the agent an hourly wage or by paying the agent a fee for each task completed. If the couple does this, then the agent has an incentive to spend her energy on efforts to sell the house. Depending on the exact payment scheme, the agent will focus on the task for which she is being directly compensated so long as the benefit is greater than the opportunity cost. The problem is that the incentive structure encourages the agent to spend time or perform tasks even if those inputs do not improve the probability of the house being sold. Moreover, if the effort is not observable by the couple, then the agent has an incentive to say that she spent time or completed tasks even if she did not. The latter result is the biggest deviation from the couple's objectives as the agent's non-action does not benefit the couple in any way. Nor is this the end of the principal-agent problems with hourly or fee-for-task payment systems in this context. The agent also would face the incentive to reject a good offer early in the process in order to spend more time either working under the hourly wage scheme or accomplishing more tasks to get a larger paycheck. From the agent's perspective, the worst scenario would be for the couple to receive a good offer without the agent having an opportunity to do anything that would justify a request for compensation. In that scenario, the couple would achieve their objective without any assistance of the agent. Since the couple does not know how any individual activity affects a potential buyer's offer or the probability that the house will be sold, the hourly or fee-for-task payment structures do not provide the right incentives for the agent to accomplish the couple's goal.

Similarly, a payment system that compensates the agent for successfully selling the house will have its own problems. Let us assume the couple decides to pay the agent a flat fee for successfully selling the house (the fee is unconnected to the sale price and is paid if the house sold). Once again, the agent is a profit-

15 The couple may wish to sell the house as quickly as possible if they need to move quickly, but we will assume that the couple wants to get the best price. 
maximizing individual and will want to sell the house to maximize her gains. Since the agent is being compensated for selling the house without any regards to her effort, she will want to minimize her costs. Thus, the agent will focus her effort on locating a buyer who will make an offer that she can convincingly portray as the "best" offer ${ }^{16}$ that the couple will get. In this scenario, the agent would prefer to get an immediate offer from a buyer without doing any work. She will not be trying to accomplish the couple's objective of getting the highest price because she is simply trying to maximize her gains from selling the house. To prevent this type of conduct, people often pay the real estate agent a commission (a small percentage of the sales price) for selling the house. This provides the agent an incentive to try to get a higher price for the home.

It is important to note that paying a commission does not necessarily result in the couple receiving the highest price. The real estate agent is still trying to maximize her profits and so will only continue to work for a higher price if doing so increases her profits at the margin. Two economists, Steven Levitt and Chad Syverson, showed that real estate agents get a higher price and are willing to wait longer when they own the home. ${ }^{17}$ The authors explain that the principal-agent problem can be exacerbated when the agent has an information advantage about what is necessary to complete the task. ${ }^{18}$ This is because the agent can use her expertise to mislead the principal as to what tasks are necessary to produce the final product and how difficult and essential those tasks are. ${ }^{19}$ The main point of this example is to illustrate that the principal-agent solution is still second-best and falls short of the optimal outcome; here, the sellers receiving the highest price.

The house-sale example provides the general framework for understanding the principal-agent problem and highlights some ways that this problem is manifest in the indigent defense context. First, it is important to remember that the principal-agent problem prevents optimal performance from occurring because the interests of the principal and the agent are in conflict, and there is asymmetric information between the two parties. Any solution will be "second-best" and will have certain defects. Thus, the goal should be to minimize the difference between actual performance by the agent and the optimal performance desired by the principal.

Second, it is important to note that within the indigent defense context there are actually two principal-agent problems: one between the State and the attorney and the other between the defendant and the attorney (State). This article will focus only on the problem between the State and the attorney, as the State is the

16 The agent will reject some offers that are too low because (1) she knows that the couple will not accept it, and (2) she will want to protect her reputation.

17 Steven D. Levitt \& Chad Syverson, Market Distortions When Agents Are Better Informed: The Value of Information in Real Estate Transactions, 90 REV. ECON. \& STAT. 599, 600 (2008).

$18 \quad I d$. at 599.

19 Id. 
principal with control over the incentive structure for the attorney. Thus, the State is the principal, and the attorneys are the agents. Like the couple trying to sell the house, the State wants to get the best outcome for the money that it pays the attorney. We can define best outcome to mean that the defendant spends the least amount of time in jail or prison ${ }^{20}$ (thus, we are assuming that the State is a perfect agent of the defendant).

Depending on the circumstances of the case, the State may want the defense attorney to get all charges dismissed, negotiate a plea bargain that minimizes the negative consequences to the defendant, or go to trial and put forth the best defense that the attorney can. Similar to the house-sale example, the State suffers from an asymmetric information problem. Just like the couple does not know the best price for their house, the State does not know which action the attorney should pursue on behalf of the defendant. As in the house-sale example, attorneys are trying to maximize their profits or utility like the real estate agent. As utility maximizers, the attorney only wants to pursue a particular action if the marginal benefit of the action exceeds the marginal cost.

The attorney faces similar dilemmas as the real estate agent depending on the payment structure. If paid an hourly wage, the attorney might spend a lot of time on the case that does not affect the outcome. This may include the attorney rejecting a "good" deal (from the defendant's perspective) at the start of negotiations to perform time-intensive tasks in order to maximize her payment. The principal-agent problem is actually exacerbated if those actions result in a longer sentence for the defendant. If the attorney is paid a flat fee for completing the case, the attorney may jump at the first deal even if the terms are not good from the defendant's perspective. Even though the house-sale example is similar to the indigent defense principal-agent problem, the solution to the problem is different because the asymmetric information problem is greater. The next part of this paper will use an economic model to investigate the problem more fully and to lay the ground work for possible solutions.

\section{ECONOMIC MODEL}

This part begins by presenting the economic model that I will apply to evaluate the influence of payment structures on attorney behavior. Part III.B gives an overview of the different payment systems and their implications. Parts III.C-F describe these systems and their implications in more detail.

20 By choosing smallest sentence length, I do not mean to ignore that there are other conditions of punishment that the defendant would be interested in. Instead, the assumption is made to simplify the problem and to make the outcomes comparable across payment systems. 


\section{A. The Model}

The model is straightforward and relies on one main assumption: attorneys are assumed to be utility maximizing individuals subject to a time constraint (T). Additionally, we will assume that the attorney's utility for a case is a function of the wage, some non-monetary benefit, and the opportunity cost of any action taken. Thus, the model can be written as:

$$
\text { (1) } \mathrm{U}\left(\mathrm{e}_{\mathrm{c}}\right)=\sum_{c=1}^{n} \mathrm{~W}_{\mathrm{c}}+\mathrm{B}\left(\mathrm{e}_{\mathrm{c}}\right)-\mathrm{C}\left(\mathrm{e}_{\mathrm{c}}\right)
$$

subject to

$$
\text { (2) } \quad \sum_{c=1}^{n} \mathrm{e}_{c}<\mathrm{T} \text {. }
$$

The intuition is this: an attorney has $n$ cases that she is working on at a given time. She must choose her effort level, $e$, for each case to maximize her utility for all cases. The term $\mathrm{B}\left(\mathrm{e}_{\mathrm{c}}\right)$ represents the non-monetary benefits that the attorney receives from the effort. The non-monetary benefits should be viewed about in several alternative ways: 1) it could be the gains in human capital (knowledge, skills, etc. that she could use in future cases) she gets from undertaking various actions; 2) it could be the utility she gets from strengthening her client's case; or 3) it could be the utility she gets from strengthening her reputation. All of these benefits are assumed to be increasing with effort but at a decreasing rate. Because of the sequencing of events, the decision to go to trial would likely result in a jump in human capital and reputation. This is because a trial presents an opportunity to use a different set of skills (presenting a case to the jury, questioning witnesses, etc.) and presents the attorney in a different way. For example, assume that you have an attorney who only tries to negotiate a plea and has never taken a case to trial. If that attorney then takes a case to trial, her reputation will improve because future threats of going to trial will be more credible.

Equation (2) represents the time constraint that every attorney faces. The attorney must choose an effort level in each case that is less than some amount (T) that she is willing to work in a time period. Returning to equation (1), the term $\mathrm{C}\left(\mathrm{e}_{\mathrm{c}}\right)$ represents the opportunity costs for the attorney. If we assume that the attorney has a fixed number of hours she is willing to work (T) in a week, then the opportunity cost of effort in one case is effort that she cannot put towards another case. If the total number of hours is not fixed, then the opportunity cost would also include the utility from the next best leisure activity that the attorney would enjoy. Utility is assumed to be decreasing as costs increase, which is why the sign for opportunity costs is negative, and does so at an increasing rate. The second part is 
a direct result of the time constraint which requires that the more time or effort she spends on a particular case, the greater impact it has on her other cases. ${ }^{21}$

Because our goal is to compare how an attorney responds to different payment schemes, the model can be simplified to looking at a single case. This allows us to drop the summation in equation (1) and the time constraint ${ }^{22}$ in equation (2). We then add the assumption that opportunity costs and nonmonetary benefits are the same for the attorney for all payment systems. With these changes made, we now can determine what level of effort maximizes utility. To do so, we take the derivative of the utility function, ${ }^{23}$ equation (1), with respect to $e$ and then set it equal to 0 . Performing this operation and rearranging the equation, the following equation results and will serve as the general framework for the analysis that follows:

$$
W^{\prime}+B^{\prime}\left(e^{*}\right)=C^{\prime}\left(e^{*}\right) .
$$

The first order-condition, ${ }^{24}$ equation (3), tells us that the attorney will choose the optimal level of effort, $e^{*}$, such that the marginal returns of the wage, $W^{\prime}$, and benefits, $B^{\prime}$, are equal to the marginal cost, $C^{\prime}$, of exerting that effort. Since we assume that $B^{\prime}$ and $C^{\prime}$ are the same for all payment systems, then any change in effort level depends on the marginal wage, $W^{\prime}$.

Now we must address a fundamental question: what is meant by effort when the agent is an attorney handling an indigent defense case for the State? Since our primary focus for comparison is between an hourly rate system and a flat fee system, it makes sense to think of effort in terms of the number of hours worked. However, hours worked are not observable by the principal; therefore, effort could be thought of as the number of hours that the attorney reports to have worked on the case.

It also is important to note that the value of the hours worked are not the same across all tasks. An hour spent explaining the case to the defendant and hearing the defendant's view on the case may or may not be as valuable as an hour spent writing a brief arguing that the case should be dismissed or that evidence should be suppressed. Thus, it may make sense to think of effort as being the number of tasks that the attorney completed on behalf of the client. Ultimately, however, the specifics of the case should dictate which of the attorney's actions are necessary or

21 Intuitively, the increasing rate assumes that the attorney gives up her least valuable time first. Thus, the more time the attorney spends, the more valuable that time is to her.

22 The time constraint still is relevant by the fact that it affects the magnitude of the opportunity costs. However, we are assuming that $\mathrm{T}$ is the same in both systems for the attorneys and so we can absorb the time constraint into the term $\mathrm{C}\left(\mathrm{e}_{\mathrm{c}}\right)$.

23 This is the standard procedure to maximize utility or profits in economics.

24 First order-condition is a term of art in economics that is a reference to the equation that results from taking the derivative of the objection function. 
appropriate. In other words, it is difficult to specify a definition of "effort." Therefore, we will assume that effort is related to the number of hours worked, although we will also discuss how different payment systems create different incentive structures that may affect both the number of hours reported and the tasks that the attorney might undertake. The following subparts describe the different payment systems and their effects in more detail.

\section{B. Basic Payment Systems and the "Hours Worked" Problem}

There are four basic payment schemes in indigent defense cases: salary, hourly wage, flat fee per case, and a lump sum to handle a type of case or a set number of cases. ${ }^{25}$ Generally speaking, each of these payment systems are associated with a particular indigent defense system. For example, the salary payment system is exclusively used when the State is using a staff Public Defender system. ${ }^{26}$ The lump sum system is used when the State has a contract with a firm to handle a particular set of cases. ${ }^{27}$ The payment system itself will attract different individuals. $^{28}$ Remember that we assume that attorneys are utilitymaximizing individuals. Thus, a salaried payment system, especially one that underpays the attorney, ${ }^{29}$ may attract individuals who value the non-monetary benefits more than some attorneys. ${ }^{30}$ However, an hourly wage system will attract attorneys who are more likely to pursue time-intensive tasks while a flat fee system is more likely to attract an attorney who is good at negotiating quick pleas (assuming the amount paid is expected to be the same). ${ }^{31}$

For the rest of the article, we will focus on the ways attorneys respond to the different payment systems rather than on how different systems might attract

25 See Robert L. Spangenberg \& Marea L. Beeman, Indigent Defense Systems in the United States, 58 LAW \& CONTEMP. Probs. 31 (1995).

26 Id. at 36.

27 Id. at 34.

28 See Michael Cragg, Performance Incentives in the Public Sector: Evidence from the Job Training Partnership Act, 13 J. L. ECON. \& ORG. 147 (1997).

29 Patrick Francois, 'Public Service Motivation' as an Argument for Government Provision, 78 J. Pub. ECON. 275, 290-92 (2000). The conclusion of this article is that the State would be better off paying a below market value salary to the Public Defenders in order to ensure that attorneys dedicated to the cause are the ones who self-select into the system. These attorneys are less likely to shirk their responsibilities because they care about the cause. However, if the salary was sufficiently high enough, then "higher" quality attorneys would self-select and would be willing to work hard enough to retain their position.

30 Because Public Defenders might have different motivations for their choice of occupation, a detailed analysis comparing salaried workers to the other groups is beyond the scope of this article.

31 Please note that this is a general assertion based on what the attorney expects to have to do for the average case. The crux of my main analysis is dealing with how the attorney will behave at the margin. In other words, it is analyzing what the attorney will consider when she has to decide whether to undertake the next task. 
different individuals. Thus, the model will analyze how a particular individual responds to the different payment systems. In other words, we are analyzing a particular attorney's decision at the margin under the different incentive structures. The question of what system is "best" is a more complicated one because of the fact that each system may attract a different set of attorneys. Thus, a more indepth discussion (which is left for future work) of the attorney selection problem would be needed if one was trying to design a new system. Primarily, we want to focus on the difference in attorney behavior when she is paid an hourly wage as compared to a flat fee.

The main difference in the model between an hourly wage system and a flat fee system is that $\mathrm{W}$ is a function of effort in the former and is a constant in the latter. If we accept the assumption that hours worked (h) are a perfect measure of attorney effort, then the attorney's utility function for the hourly system can be written as:

$$
\mathrm{U}(\mathrm{h})=\mathrm{W}(\mathrm{h})+\mathrm{B}(\mathrm{h})-\mathrm{C}(\mathrm{h})
$$

whereas for the flat fee system it would be:

$$
\mathrm{U}(\mathrm{h})=\mathrm{W}+\mathrm{B}(\mathrm{h})-\mathrm{C}(\mathrm{h})
$$

Thus, when we look at the attorney's utility maximizing decision (see equation (3)) $W^{\prime}=$ hourly rate in the hourly wage system and $W^{\prime}=0$ in the flat fee system. Based on the assumption that $\mathrm{B}^{\prime}\left(\mathrm{e}_{\mathrm{t}}\right)$ and $\mathrm{C}^{\prime}\left(\mathrm{e}_{\mathrm{t}}\right)$ are the same in both systems, this means the attorney who is paid an hourly rate will work more hours, at the margin, than an attorney paid a flat fee. This result makes sense that an attorney would spend more time to complete a case when paid an hourly wage instead of a flat fee. The magnitude of the increase in hours between the hourly system and the flat fee system will depend on the relative difference between the hourly rate and the opportunity cost of the attorney's time. On average, a higher wage will lead to more hours worked, holding all else constant. This is because the attorney will value more an extra hour with a higher wage than with a lower wage.

The other factor that can affect the magnitude of the increase in hours is the magnitude of the opportunity cost for the additional hours. If $W^{\prime}+B^{\prime}(h)$ is always less than $C^{\prime}(h)$, then the attorney will behave similar to when she is being paid a flat fee. The attorney will want to spend her resources resolving the case as quickly as possible because her marginal utility under these conditions is always negative. ${ }^{32}$ The inequality is likely to occur when the attorney has a full private case load or when the attorney has a market wage that is significantly larger than

32 If given the choice, the attorney would choose not to take the case. However, if the attorney is required to take any case assigned to her, then this analysis is relevant. 
an indigent defense wage. Ultimately, this scenario is likely to result in a similar level of effort regardless of the payment system. The key reason for this result is that we assumed that hours are a perfect measure for effort. In other words, we need to assume that all hours are valued the same; thus, we can say that spending the same amount of time is the same as putting forth the same effort in the case. This would also require that hours worked be perfectly observable, which is not a reasonable assumption. Because hours worked are not perfectly observable, the task of valuating effort becomes more difficult because we cannot evaluate how the attorney is spending her time. We will relax these assumptions as the consequences of the hourly rate system are introduced in the next section.

\section{Consequences of the Hourly Rate System}

Each payment system has its own array of consequences that result from the incentive structure. Once we relax the assumption about hours worked being observable, the most obvious consequence of the hourly rate system is that attorneys now have the incentive to inflate their hours. The attorney can accomplish this either by simply misreporting her hours or by dragging out activities. The problem in either scenario is that the additional hours the State must pay for do not add value to the case.

To be more precise about the incentives at work, the model can demonstrate that the attorney will inflate her hours as long as it does not trigger the State auditing her. In other words, the marginal cost, $C^{\prime}$, of misreporting her hours is just the marginal change in probability that the State will suspect that she is lying and punish the attorney. The attorney cares about the expected cost, which is the probability of being detected times the severity of the punishment. Since the attorney works out of her office, it is difficult for the State to monitor the attorney's behavior. Thus, the severity of the punishment must be severe to deter the attorney from running up meaningless hours.

Additionally, the hourly rate system may result in the attorney altering how she spends her time on the case. Hourly payment systems tend to treat every hour that the attorney works as being of equal value with the exception that some jurisdictions pay a premium wage for time spent in court. This premium may represent the State's belief that in-court hours are more valuable than out-of-court hours. ${ }^{33}$ The result of treating all hours equally is that the attorney may not spend her time on the activities that best serve her client. This is because some activities have a higher opportunity cost than other activities.

For example, the attorney may want to spend more time on legal research because that activity builds human capital and may be beneficial to the attorney in

33 It could also be the case that these courts are easier to monitor, because the hours are observed by other members of the court, and thus the State is willing to compensate the attorney at a wage closer to market value because it can verify them more easily. 
future cases. However, the attorney may not want to spend a lot of time investigating a case because there is some risk that the investigation will not turn up any valuable information. Therefore, the attorney's level of risk aversion might affect the type of activities that the attorney undertakes. If the attorney is risk averse, then she would want to undertake activities that have a high probability of being successful or have a high potential payoff.

Furthermore, the fact that hours worked are not perfectly observable creates an incentive for the attorney to focus on activities that are not easily observable and have a large variation in the expected time to complete the task. An attorney will focus on such activities because those hours are easier to inflate. The combination of those two characteristics makes it difficult for the State to catch an attorney who is inflating her hours. Thus, an attorney would want to limit the number of in-court hours because they are observed by other members of the court and difficult to inflate. An hourly rate system that compensates attorneys for all activities equally is unlikely to result in attorneys performing optimally.

\section{Consequences of the Flat Fee System}

The flat fee system also has some consequences that result from the specific payment structure. The most obvious consequence is that the attorney's pay is the same whether she settles the case in ten minutes or she takes the case to a long and time-consuming trial. Essentially, the attorney is being paid to complete the case and so she is going to exert her effort on tasks that dispose the case. She is only going to undertake tasks that have an expected marginal benefit that is greater than the opportunity cost of the activity since there is no compensation directly related to her time. Furthermore, the attorney is unlikely to pursue activities that are timeconsuming since the attorney essentially wants to minimize costs. Instead, the attorney will focus on activities that have the largest marginal, non-monetary benefit, which are activities that help her reputation, help build her human capital, and improve her client's case. Thus, the attorney would likely undertake actions that increase the chance of dismissals, with the dearth of these activities depending (among other things) on the attorney's risk aversion. If the attorney is unable to get the case dismissed, the attorney will then want to settle as quickly as possible. The quicker the case settles the higher the attorney's effective wage (flat fee divided by the number of hours worked) will be. If the attorney has private cases that are paid an hourly rate, this may affect how she settles cases because she has a time constraint and is directly compensated for those hours. She will want to settle quickly on the flat fee case so that she can spend time on her other cases.

In the final analysis, the flat fee system makes it difficult to imagine a scenario where the attorney is fulfilling the spirit of her constitutional duties under Strickland v. Washington. ${ }^{34}$ As the Strickland Court noted, "[t]he Sixth

34 Strickland v. Washington, 466 U.S. 668 (1984). 
Amendment recognizes the right to the assistance of counsel because it envisions counsel's playing a role that is critical to the ability of the adversarial system to produce just results." 35 The incentive structure of the flat fee system encourages the attorney to look for a major flaw in the prosecutor's case and to try to get the case quickly dismissed. If that is not possible, then the attorney will want to settle quickly. This approach seems to be non-adversarial in nature and falls short of the constitutional requirement. However, it may be difficult to prove that representation warrants relief on the part of the defendant. ${ }^{36}$

\section{E. Lump Sum Payment}

A third typical payment system exists when the State pays a law firm a lump sum to handle a certain type or set number of cases. A key difference in this payment system is that the State hires a firm instead of an individual. The goal of a firm is assumed to be profit-maximizing instead of utility-maximizing. Thus, equation (1) would look like the following in the case of a firm:

\section{(4) $\quad \Pi=$ Total Revenue - Total Costs.}

In this case total revenue is the lump sum that is specified in the contract. Since this lump sum does not depend on attorney effort in any way, the goal of the firm is to minimize cost. ${ }^{37}$ Thus, the firm will want to focus on tasks that quickly resolve the case with as little time, effort, and other resources as possible. Moreover, since these contracts are usually obtained through an auction mechanism where the lowest bidder wins, the firm has an incentive to understate its costs in order to win the bid. Thus, the firm is likely to cut corners in order to make itself profitable. This is because any additional cost-saving that the firm enjoys would directly profit the firm. This incentive structure almost surely fails to meet the standards of Strickland, and districts using it have been subject to successful constitutional challenges. ${ }^{38}$

\section{F. Hourly Rate with a Firm Cap}

Some systems use an hourly rate system but then cap the total amount that the attorney can be paid for a case. The attorney in this scenario should behave like the attorney under the hourly system up to the point that the attorney reaches the

$35 \quad I d$. at 685.

36 Id. at 687 . The defendant must prove that the representation falls below the constitutional requirement and that the result of the case would have been different.

37 Cost would have to include the potential of being re-hired in the future if there is some kind of evaluation process.

38 Wilbur v. City of Mount Vernon, 989 F. Supp. 2d 1122, 1132-33 (W.D. Wash. 2013). 
maximum. At that point, the attorney is essentially being paid a flat fee and would begin to behave like the attorney who was paid a flat fee from the outset. While this may be the expected outcome, the attorney under the capped-hourly system might have an even stronger incentive than attorneys in the flat fee system to resolve the case quickly. The attorney may feel like any additional work is free because the State is no longer compensating them for any additional work. The capped-hourly system also incentivizes attorneys who are close to the cap to drag out the case (or lie about their hours) in order to reach the cap and get the maximum payment, but then close the case shortly thereafter. Thus, this system may not reduce cost or improve quality as attorneys might ensure they reach the cap rather than close the cases quickly or invest additional time, effort, and other resources to obtain the optimal result for the client.

\section{EVIDENCE FROM SOUTH CAROLINA ${ }^{39}$}

With the economic model and its implication in mind, we now turn to a realworld application by empirically evaluating how incentives affected hours reported by private counsel in South Carolina's indigent defense system when the payment system changed from an hourly rate to a flat fee. In November of 2012, the Supreme Court of South Carolina issued an amended administrative order that drastically changed how private attorneys handle indigent defense cases. ${ }^{40}$

\section{A. What Changed with the New System?}

The South Carolina Commission on Indigent Defense (Commission) implemented three major changes, including switching to a flat fee system. The first change affected who was eligible to receive indigent defense cases. The second affected how cases were assigned to the attorneys deemed eligible to receive cases. Finally, the Commission switched the payment incentive structure. It is important to understand how these changes may have impacted the average number of hours reported in order to identify the "incentive effect." 41

First, the Commission changed who was eligible to receive cases by switching from an assigned counsel system to a contract system. Under the hourly rate system, every attorney in the State who was not part of an exempted class was

39 Data and calculations presented in this section are based on the raw data obtained by the Author from the South Carolina Commission on Indigent Defense in December 2014 and are on file with the Author.

40 Supreme Court of S.C., Amended Administrative Order (Nov. 2, 2012), https://www.sccid. sc.gov/resources/docs/608_Order_of_Chief_Justice.pdf [https://perma.cc/XA32-XTLC].

41 Edward P. Lazear, Performance Pay and Productivity, 90 AM. ECON. Rev. 1346, 1346-47 (2000). The Lazear article notes that there are two competing effects with different payment structures: a selection effect and an incentive effect. The incentive effect identifies the change in productivity that results from being paid on the basis of output instead of being paid for your input. 
required to register to participate in the indigent defense system. ${ }^{42}$ The attorney's only choice was whether to receive civil cases or criminal cases. ${ }^{43}$ When the Commission switched to the flat fee system, it also changed to a contract system. Thus, attorneys are required to apply to and be selected by the Commission in order to be eligible to receive indigent defense cases. ${ }^{44}$ The contract attorneys represent a subset of attorneys who received cases under the hourly rate system. This could create a selection effect where the Commission would select the attorneys who take less time, on average, to complete a case under the hourly rate system. ${ }^{45}$ The selection effect would lead to a reduction in the number of hours reported just because those attorneys spent less time, on average, on a case in the first place. In order to control for this, we can just look at cases where the attorney participated under both regimes.

Second, the Commission changed how it assigned cases. Under the hourly rate system, assignment was essentially a random lottery. Once an attorney selected a category and county for which she would be willing to accept cases, the cases would be assigned out alphabetically by the two categories. ${ }^{46}$ Under the flat fee system, criminal cases are no longer required to be distributed alphabetically. ${ }^{47}$ Thus, the Public Defender's Office can attempt to better match cases to the attorney and can try to balance the attorney's workload.

Finally, the Commission changed how attorneys are compensated. The old system paid attorneys an hourly rate based on the number of hours they reported. The rate depended on two things: 1) whether the time was reported as being incourt versus out-of-court, ${ }^{48}$ and 2 ) the type of case the attorney was handling. For example, an attorney handling a felony case would get paid $\$ 50$ an hour for out-ofcourt work and $\$ 75$ for in-court work. The new system pays the attorney a flat fee of $\$ 900$ for the case regardless of whether the case was a felony or a misdemeanor and regardless of how the attorney spent her time. ${ }^{49}$ This is the main change that we want to analyze, as it shows how payment structure can affect attorney behavior.

\footnotetext{
42 S.C. App. Ct. Rule 608.

43 Id.

44 Id.

45 Lazear, supra note 41.

46 S.C. App. Ct. Rule 608(f)(2)(A).
}

47 The civil side underwent more changes to the system that might lead to efficiency gains. Because these changes did not affect the criminal side, they are omitted from the discussion here. The results are similar when including civil cases.

48 The attorney was paid a $50 \%$ premium for hours spent in court.

49 Agreement for Attorney Services (Criminal Conflict) 1, at 2, https://www.sccid.sc. gov/resources/docs/608\%20Contract/608\%20Contract\%20(Criminal).pdf [https://perma.cc/9LVFUAWA]. 


\section{B. Data}

The Commission provided the data that will be used to analyze the incentive effect. The Commission is the governmental agency that is tasked with providing legal services for indigent defendants. As part of its course of business, it collects information on hours that the attorney reported along with other case information. However, the Commission does not collect information concerning the outcomes or sentences of those cases. Thus, we are not able to analyze how the different incentive structures affect the end result for the defendants.

The Commission provided case level data for private indigent defense cases for the time period of October 2006 until November 2014. The original data consisted of about 20,000 criminal cases. ${ }^{50}$ The information includes the number of hours spent on the case (broken down between in-court hours and out-of-court hours), the type of case, how many charges the case involved, the specific charges, the county it was litigated in, an attorney identifier that allows the analysis to track attorneys across cases, and an indicator that specifies the payment system under which the attorney was compensated.

\section{Discussion of Statistics}

Table 1 provides an interesting look at how incentives can impact attorney behavior. This table shows the total change in hours reported between the hourly system and the flat fee system.

Table 1. Summary Statistics by Attorney Type

\begin{tabular}{l|cc|cc}
\multicolumn{1}{c}{ Hourly System } & \multicolumn{2}{c}{ Flat Fee } \\
\hline \multicolumn{1}{c}{ Variable } & Mean & Std. Dev. & Mean & Std. Dev. \\
\hline Total Hours & 19.44 & 45.67 & 8.50 & 12.10 \\
Out of Court & 17.67 & 42.80 & 7.65 & 10.01 \\
In Court & 1.76 & 5.90 & 0.85 & 3.52 \\
In Court Ratio & 0.103 & 0.15036 & 0.070 & 0.118 \\
No. of Charges & 2.21 & 2.31 & 2.31 & 2.46 \\
\hline $\mathrm{N}$ & 19032 & & 1242 & \\
\hline
\end{tabular}

The difference in average total hours between the two systems is statistically significant. Furthermore, it shows that attorneys reduce the number of hours they are reporting by about $56 \%$ when they are paid the flat fee compared to when they were paid an hourly rate. Some of the difference in the hours may be a change in the reporting habits of the attorneys. They may have inflated their hours under the hourly system and now report them more accurately. Thus, in-court hours may be

50 The full data set is about 44,000 cases when the civil cases are included. 
a better indicator of attorney effort, because those hours are more difficult to inflate. Still, attorneys reported $51 \%$ less hours spent in court under the flat fee system. This is still a significant reduction in hours, both statistically and economically. One issue that Table 1 does not address is the change in compensation of attorneys after the change. Thus, some of this reduction may be the result of the selection effect (meaning the attorneys who resolved cases more quickly are more likely to participate in the flat fee system).

Table 2 presents the same statistics except that the statistics for the hourly system only include cases that the attorney worked under the flat fee system. In other words, this data set is restricted to attorneys who worked in both systems.

Table 2. Summary Statistics by Attorney Type-Same Attorneys

\begin{tabular}{l|cc|cc}
\multicolumn{1}{c}{ Hourly System } & \multicolumn{2}{c}{ Flat Fee } \\
\hline Votal Hours & Mean & Std. Dev. & Mean & Std. Dev. \\
Out of Court & 17.17 & 28.32 & 8.50 & 12.10 \\
In Court & 15.79 & 25.18 & 7.65 & 10.01 \\
In Court Ratio & 1.39 & 4.66 & 0.85 & 3.52 \\
No. of Charges & 0.083 & 0.135 & 0.070 & 0.118 \\
$\mathrm{~N}$ & 2.31 & 2.30 & 2.31 & 2.46 \\
\hline & 5514 & & 1242 & \\
\hline
\end{tabular}

The difference in the means for the hourly systems between Table 1 and Table 2 is statistically significant at the $10 \%$ level. This finding supports that attorneys that reported more hours may not participate in the flat fee system (at least some of them did not participate). However, focusing on the incentive effect, attorneys still reduced the number of hours they reported by $50 \%$ under the flat fee system compared to the hourly system. The bigger change is the number of in-court hours reported for this subset of attorneys. These attorneys only reduced the number of in-court hours by about 39\%. If we accept the premise that in-court hours are a better measure of attorney behavior, then we still find a large decrease in attorney effort. This would also suggest that attorneys, on average, may inflate their hours by about $10 \%$.

Although the two systems have the same number of average charges, another factor that could explain the change in behavior would be if the attorneys in the flat fee system are working easier cases. An imperfect measure of case difficulty is the severity of the charge. It would be problematic if flat fee attorneys receive a disproportionate number of misdemeanor cases compared to hourly rate attorneys. Table 3 presents the distribution of case types under the two payment systems. 
Table 3. Breakdown of Criminal Case Type by Fee Structure

\begin{tabular}{|c|cc|cc|}
\multicolumn{1}{c}{} & Hourly & Percent & Flat Fee & Percent \\
\hline Felony U & 257 & 5.61 & 66 & 6.41 \\
Felony A & 541 & 11.81 & 148 & 14.37 \\
Felony B & 59 & 1.29 & 17 & 1.65 \\
Felony C & 180 & 3.93 & 23 & 2.23 \\
Felony D & 690 & 15.06 & 171 & 16.60 \\
Felony E & 783 & 17.09 & 185 & 17.96 \\
Felony F & 761 & 16.61 & 213 & 20.68 \\
Misdemeanor A & 182 & 3.97 & 63 & 6.41 \\
Misdemeanor B & 14 & 0.31 & 9 & 0.87 \\
Misdemeanor C & 121 & 2.64 & 28 & 2.72 \\
Misdemeanor U & 994 & 21.69 & 107 & 10.39 \\
\hline Total & 4582 & 100.00 & 1030 & 100.00 \\
\hline
\end{tabular}

The types of cases that the attorneys handled under each regime seem similar. The biggest difference is that hourly attorneys handled a significantly larger percentage of unclassified misdemeanor cases. Since these are the least-severe crimes, we expect these cases to require the least amount of time. This would not explain the reduction of hours between the two systems, however, since the hourly system should have a lower average because of the disproportion of "easier" cases.

These summary statistics indicate a decrease in the mean number of hours being reported between the flat fee system and the hourly system. While some of the reduction may be the result of a change in reporting behavior, the in-court hours also decrease by almost $40 \%$ under the flat fee system. Since these hours are more difficult to inflate, this reduction suggests that attorneys do reduce their level of effort, on average, when they are paid a flat fee. This result provides evidence that supports the prediction made in Part III.A. However, it is unknown how the reduction in hours affects the ultimate outcome of the case.

\section{POSSIBLE IMPROVEMENTS}

Before one can discuss how any indigent defense system can be improved, one must understand the overall goal of the indigent defense system. The State's objective is to provide the best representation for all indigent defense cases given its budget constraint. The key assumption here is that the budget is fixed across all systems. It is almost surely true that increasing the indigent defense budget in order to hire more attorneys, pay current attorneys better, or to improve the support staff would improve the indigent defense system. However, these arguments are beyond the scope of this article. Instead, we will talk about how an incentive system can be designed to reduce the deviation between attorney performance and the State's objective in the context of systems employing private counsel. 


\section{A. The Multiple Task Problem}

The general problem the State faces is that the attorney has an informational advantage for any particular case. ${ }^{51}$ This makes it difficult to judge what actions the attorney should undertake and what actions are a waste of resources. The State is left dealing with a principal-agent problem where the agent needs to complete multiples tasks ${ }^{52}$ in order to achieve the principal's objective of providing quality representation.

Holmstrom and Milgrom developed a formal theoretical model to analyze how an optimal contract design could be used to address the multi-task principalagent problem. ${ }^{53}$ The main point the authors made is that it becomes difficult to provide the proper incentives to produce goods and services that require a variety of tasks be completed for production of the final product. ${ }^{54}$ This is because the agent will devote her effort to completing tasks for which she is directly being paid to complete. ${ }^{55}$ Thus, "the desirability of providing incentives for any one activity decreases with the difficulty of measuring performance in any other activities that make competing demands on the agent's time and attention." 56 This becomes more true if the quality of the service is difficult to measure. ${ }^{57}$ If the agent is being paid to complete a task and quality is difficult to measure, the agent will increase production at the expense of quality. ${ }^{58}$ It is important to understand this problem and its application before we can improve any particular system.

\section{B. Three Different Systems but the Same Problem}

There are essentially three different systems that could be used to compensate a private attorney handling indigent cases: pay her an hourly wage, pay her a flat fee for the case or set of cases, or pay her a fee for each task that she completes. While these three systems present different incentives, they all suffer the same problem: they reward the attorney for a certain action without any assurance of quality.

The hourly wage system rewards the attorney for spending time on the case. However, as previously discussed, this system does not necessarily result in the attorney spending the hours on the tasks that are most beneficial to the client. This

51 See Levitt \& Syverson, supra note 17, at 599.

52 The multiple tasks could be simplified to two: 1) resolving the case and 2) a quality measure.

53 See Holmstrom \& Milgrom, supra note 13.

54 Id. at 25.

55 Id.

56 Id. at 26.

57 Id. at 25.

58 See id. 
might be especially true if the attorney is risk averse and there is uncertainty about how beneficial the action will be. Furthermore, hours are difficult for the State to monitor, especially out-of-court hours, and so the State may pay the attorney for hours that are wasted or misreported. The summary statistics from South Carolina support the conclusion that attorneys may inflate their hours when paid an hourly rate. They also support the conclusion that attorneys change effort when they are paid a flat fee.

The flat fee system rewards the attorney for resolving the case, but it does not necessarily incentivize the attorney to challenge the prosecutor's case. This fact is illustrated by the idea that the attorney is paid the same amount for a case that settles with a ten minute phone call and a case that results in a long, timeconsuming trial. As previously discussed, this does not mean that the attorney will completely shirk on her duties as she should be just as happy, perhaps even more happy, if the case is dismissed because of a major hole in the prosecutor's case as opposed to a plea agreement. Thus, the difficulty from the State's perspective is that it can be difficult to measure the quality of a case's disposition.

A system that pays the attorney for completing specific tasks rewards the attorney for performing those actions. There are two big consequences for this system: 1) it incentivizes the attorney to complete the actions regardless of whether the action needs to be taken; and 2) it dis-incentivizes the attorney from undertaking any action that does not result in her being compensated. The second point is that the attorney will choose to undertake a task that she will be compensated for over a task for which there is no compensation. Let's assume that the State was able to identify what actions are likely to improve the client's case, on average. This system dis-incentivizes the attorney from taking advantage of the informational advantage that she has for the particular case. Certainly, no two cases are identical and while one action might be beneficial in most cases, it may be prejudicial in the particular case at hand. Attorneys are retained to take advantage of their knowledge and experience and to craft a strategy for the specific case at hand. A system that prescribes certain actions to be taken eliminates this advantage.

Additionally, the State still does not possess a way to monitor the quality of the action that the attorney takes. For example, a State pays some fixed amount if the attorney files a motion to suppress the evidence. The result will be that the attorney files the motion, but there is no way to judge the quality of the motion. The attorney may spend 20 minutes drafting the brief with some generic challenge or the attorney may spend several hours drafting a well-thought argument challenging police action. If you pay for the completion of the action, there is no way to guarantee the quality of the attorney's work or that the work is necessary. ${ }^{59}$ However, this incentive structure suggests that the attorney is likely to undertake

59 The judge is a potential arbitrator as to whether the action is necessary, but that only works for actions that involve the court. 
the action and possibly shirk on the quality. This problem is amplified if the action is difficult for the State to observe. The State can at least observe from the court record that a motion was filed; however, it is difficult for the State to monitor whether the attorney completed any related tasks. Thus, like the hourly rate system, attorneys may claim to have completed these tasks even though they did not.

\section{Monitoring as a Solution}

The main takeaway from Holmstrom and Milgrom's paper is that the principal should reward the agent for actions that are observable and to use job design to ensure consistency in actions that are unobservable. ${ }^{60}$ In other words, the State will want to incentivize actions that the State can easily monitor. These actions include in-court work, tasks that can be found as part of the court record, and the disposition of the case. Said tasks are observable only upon completion, but the incentive structure must be designed to ensure some measure of quality is met.

In-court hours are probably the easiest to ensure a quality measure. That is because the judge and prosecutor are also present for these hours. Because attorneys are often repeat players in the same court, it seems unlikely that the attorney will pursue unnecessary, or low quality, hours in court since the attorney's reputation is at stake. If the attorney gets a reputation for wasting the court's time, the judge may treat her unfavorably in future cases, which is something no attorney wants.

Tasks that are part of the court record may have an obvious measure of quality. Examples include filing various motions, trials, and meeting with a client (such as through visitation records). The obvious measure of quality is whether the action is successful. Consider a motion to suppress evidence based on an invalid police search (assume the police improperly searched the premise without a warrant). One way to measure quality is if the evidence is actually suppressed in the case. Now, certainly there will be cases where a "low-quality" motion results in the evidence being suppressed and other cases where a "high-quality" motion does not get the evidence suppressed because of other factors. This is why the better incentive structure will provide a small fee to mitigate some risk that the action will not be successful and then provide a second fee if the action is successful. ${ }^{61}$ The keys are that the first fee must not be so large that every attorney will want to undertake it and that the second payment must be sufficiently larger than the first so that the attorney will want to do a "good" job. The decision from

60 Holmstrom \& Milgrom, supra note 13, at 25-26.

61 Paying a fee for certain actions has its own issues. However, this solution uses monitoring to ensure some quality while still mitigating some of the risk for the attorney. 
the attorney's perspective is that the task must have a higher expected payout than the opportunity cost for undertaking the action.

\section{Monitoring Actions with Uncertainty}

The quality of the disposition of the case may be the most difficult metric to evaluate because any given case has a lot of factors that can affect the outcome, and the defense attorney's action is only one variable. Wright and Peeples suggest one way to measure the quality of an attorney's performance is to identify how attorneys perform with respect to the average sentence length for a case with similar charges. ${ }^{62}$ The article proposes an attorney rating system based on how much value the attorney adds to a particular case. ${ }^{63}$ The authors estimate value by comparing the standard deviation of the defendant's sentence and other cases that would be similar under the North Carolina sentencing guidelines. ${ }^{64}$ The assumption is that a shorter sentence compared to the average length in similar cases must be attributed to the attorney.

This is an interesting proposal that puts several factors in play: 1) it may be limited to jurisdictions that have a sentencing guideline $;{ }^{65}$ 2) random assignment of cases is a necessary condition to analyze attorney performance; 3 ) the analysis shows the limitation of small data sets; and 4) the measure should probably be included with other measures of quality. ${ }^{66}$

The first limitation of the method might be that it only applies to jurisdictions with sentencing guidelines. The "value-added" concept relies heavily on identifying the proper counterfactual. In other words, to determine the value of the attorney, one must correctly imagine a world where another attorney handled the case. Wright and Peeples choose the counterfactual in which the theoretical attorney achieves the average reduction in the length that would be expected under the sentencing guidelines based on the charge and criminal history. ${ }^{67}$ The analysis takes advantage of having an easily identifiable starting point: where the conviction falls on the sentencing guideline table. Thus, it may be difficult to apply such analysis to jurisdictions that do not use sentencing guidelines. ${ }^{68}$ The

62 Ronald F. Wright \& Ralph A. Peeples, Criminal Defense Lawyer Moneyball: A Demonstration Project, 70 WASH. \& LEE L. REV. 1221, 1245 (2013).

63 Id. at 1243-44.

64 Id.

65 Id. at 1241-42. Jurisdictions that use sentencing guidelines are in the minority. See SENTENCING Guideline ReSEARCH CTR., http://sentencing.umn.edu [https://perma.cc/X6C7-DJMX] (last visited Mar. 15, 2017).

66 See Wright \& Peeples, supra note 62, at 1250-51.

67 Id. at 1242-44.

68 It seems likely that attorneys would argue what the proper counterfactual is since their pay is dependent upon that fact. 
sentencing guidelines do give a pretty strong anchor point and help to identify the attorney's value. ${ }^{69}$

The analysis also requires cases being randomly assigned to attorneys. If attorneys have the ability to select their cases, then they will try to identify the cases where they are able to reduce the sentence length the most compared to the mean. ${ }^{70}$ Thus, the metric would no longer identify the attorney's value-added to a particular case as the attorney's ability to cherry-pick favorable cases would muddle the results. To be completely thorough, one should test the assignment mechanism to determine if the assignment is random or only claims to be. ${ }^{71}$ Random case assignment is necessary to identify causal effects for any study.

Wright and Peeple's analysis also shows some shortcomings of the data they had available to them. The authors attempted to identify what factors are correlated with an attorney's success and primarily found statistically insignificant results. $^{72}$ The insignificant results are a product of not having enough power in their data to be able to identify all of the factors. They used 215 observations $^{73}$ and were trying to identify almost 30 variables. $^{74}$ They were probably just asking too much of the data to be able to identify the correlations, especially considering they used numerous dummy variables. The key is to make sure that the data has enough observations and variation in the independent variables to be able to identify their impact on the dependent variable. ${ }^{75}$

Lastly, the value-added measure with respect to sentence-length reduction should just be one measure of quality resolution. ${ }^{76}$ Among the examples of additional quality measures, client satisfaction seems to be an obvious choice. The attorney is supposed to be an agent of the defendant; therefore the defendant should be an input in the evaluation of attorney performance. Incorporating client perspectives into the evaluation process will provide some incentive for the attorney to take actions that may not directly resolve the case but may be seen as a measure of quality representation. For example, the attorney may take the time to

69 Jurisdictions with no sentencing guidelines may use other forms to try to identify a similar starting point. This task should be feasible, but does not have a more ambiguous starting point. Thus, careful consideration must be taken as to what is the correct counterfactual.

70 Wright \& Peeples, supra note 62, at 1265.

71 An example of the test can be found in Michael A. Roach, Indigent Defense Counsel, Attorney Quality, and Defendant Outcomes, 16 AM. L. \& ECON. REV. 577, 596-97 (2014).

72 Wright \& Peeples, supra note 62, at 1251-60.

73 They observed lawyers with sentencing records in felony cases that were charged in 2006 and resolved by 2010.

74 Wright \& Peeples, supra note 62, at 1252-60.

75 For a rule of thumb, see Carmen R. Wilson Van Voorhis \& Betsy L. Morgan, Understanding Power and Rules of Thumb for Determining Sample Sizes, 3 TUTORIALS IN Quantitative Methods For Psych. 43, 48-49 (2007).

76 Wright \& Peeples, supra note 62, at 1262-66. 
explain the charges and potential consequences to the defendant in order for the defendant to understand why the attorney is taking certain actions. ${ }^{77}$

The best way to use this information would be to create a composite score that ranks all attorneys who are eligible to receive indigent defense cases in a jurisdiction. The jurisdiction must determine how it wants to weigh each of the different factors when creating the composite score. Such a ranking could be used to ensure that higher-ranked attorneys are more likely to receive cases in the future or it could be used to match attorneys to cases where they have a history of success. A key for the ranking system to be functional is that the manager must understand the limitations of the system. Managers need numerous observations of the attorney's performance before they can properly evaluate her performance. Also, the manager will want to account for a change in performance as the attorney gains more experience (this is especially true for newer attorneys). Additionally, this mechanism could then be used to reward high-performing attorneys by increasing their wage.

\section{E. Monitoring to Ensure Accountability}

Agents are less likely to shirk on their responsibilities when they are expected to have repeat interactions with the principal. ${ }^{78}$ Repeat-player interaction is a powerful solution to the principal-agent problem because potential future wages creates an incentive for the agent not to shirk her duties. ${ }^{79}$ Thus, a key to improving any indigent defense system is to introduce a strong measure of accountability. This requires the system to have some measure of attorney performance to identify underperforming attorneys. The system needs to institute some punishment stage to promote accountability for the attorney's performance. Potential punishment could vary: reduction in payment, some form of probation, a requirement to attend some training course, a reduction in caseload, or full banishment from receiving cases in the future.

The two factors that will curb attorney's shirking and cheating are the strength of punishment and the credibility of the threat. In other words, the attorney cares about the expected punishment which is the product of the probability of being punished and the severity of the punishment. Because small sample sizes can skew results, the most prudent course would seem to be some incremental system where small deviations are handled with lesser punishments. The ranking system from

77 See, e.g., Christopher Campbell et al., Unnoticed, Untapped, and Underappreciated: Clients' Perceptions of their Public Defenders, 33 BeHAV. SCI. \& L. 751 (2015); Janet Moore et al., Make them Hear You: Participatory Defense and the Struggle for Criminal Justice Reform, 78 ALB. L. REV. 1281 (2015).

78 Roy Radner, Repeated Principal-Agent Games with Discounting, 53 ECONOMETRICA 1173, 1174 (1985).

79 Id. 
the previous section could serve as a monitoring system. If defendants are consistently giving the attorney negative reviews, then it may be prudent to require the attorney to attend some training workshop (similar to what you expect within a public defender office). If the attorney is constantly underperforming based on outcome measures, it may be prudent to put the attorney on some kind of probation where the attorney's actions are monitored by the public defender office and the wages are reduced to account for the increase in cost to the State. If these problems persist or if the attorney commits some gross misconduct, then the attorney should be prohibited from receiving cases in the future.

\section{CONCLUSION}

Incentives matter and can have an impact on how an individual behaves. Different payment systems promote different behavior, and attorneys will respond to the different incentives in a predictable manner. This article used a simple economic model to illustrate how incentives can affect attorney behavior. The model predicts that attorneys who are paid an hourly rate will work more hours at the margin than attorneys who are paid a flat fee. The hourly rate also incentivizes the attorney to inflate the number of hours they report. This is because the attorney's compensation is directly tied to the number of hours reported. The model also predicts that attorneys will focus on activities that are not easily monitored and have a large variance when they are paid an hourly rate. Alternatively, the model predicts that attorneys will want to focus on activities that promote settling a case when they are paid a flat fee. This is because the attorney is paid the same amount whether the case is resolved by a 10-minute phone call or a lengthy trial.

South Carolina's indigent defense system provided a natural quasi-experiment to analyze how different incentive structures affect attorney behavior. This is because the State's indigent defense system changed how it paid outside counsel who handled indigent defense cases. South Carolina switched from paying these attorneys an hourly rate to a flat fee. Using data provided by the South Carolina Commission on Indigent Defense, I presented summary statistics that showed how the mean number of hours differed between the two systems. Furthermore, because we are able to identify what attorneys worked in both situations, we are able to better identify the incentive effect. When looking at just attorneys who participated in both systems, we find that mean number of hours reported decreases by $50 \%$ when the attorneys are paid a flat fee compared to an hourly rate. Since this could just be a change in reporting habits, I look at how in-court hours change, because in-court hours are more difficult to arbitrarily inflate by the attorney. Considering only the in-court hours, we find that the mean number of hours still decreases by about $40 \%$ for the flat fee system compared to the hourly rate system. These findings are consistent with the model's prediction that attorneys will exert less effort under a flat fee regime. 
Finally, I offered some ways that any indigent defense system can be reformed. The key steps for any reformation project should be focused on introducing more monitoring and accountability. One must think about the tradeoffs that any system will possess and focus on compensating attorneys for actions that are observable in order to limit wasting valuable resources. One monitoring tool could be introducing a ranking mechanism that attempts to quantify the value that the attorney adds to any particular case. This mechanism could then be used to reward high-performing attorneys by increasing their wage or by giving them preferential treatment in case assignment. It also could be used to identify which attorneys need a push to perform better. The push could be something minor like attending a training workshop or it could be something major like dismissal from the indigent defense system. The main point is that monitoring and accountability provide the State with the tools to ensure that the spirit of the constitutional requirements of Strickland is being met. 